\title{
More Than Just a Vet? Professional Integrity as an Answer to the Ethical Challenges Facing Veterinarians in Animal Food Production
}

\author{
Franck L. B. Meijboom ${ }^{1}$ (D)
}

Accepted: 3 August 2017 / Published online: 21 August 2017

(C) The Author(s) 2017. This article is an open access publication

\begin{abstract}
Veterinary ethics in the context of food production is a special case that is in need of additional reflection from philosophy and veterinary professionals. To substantiate this claim two developments will be presented and analyzed in order to show the current challenges facing veterinarians specialized in farm animal health. First, I argue that in the context of farm animal health and welfare the plurality of views on the moral standing of animals evokes special difficulties. A second development focuses on the changing expectations with regard to the veterinary profession and the related extending range of competences a veterinarian needs in order to work in the agri-food sector. Next, I sketch three scenarios, often meant to deal with these developments in practice, and show that they deny the moral pluralism and the genuinely moral character of the professional responsibility of a veterinarian. Finally, I claim that professional codes or standards are important, but are insufficient to deal with these developments. I end with some remarks on the importance of professional integrity. I argue that veterinarians working in the agri-food sector need to maintain an independence from the concerns and interests of stakeholders to effectively deal with ethical challenges.
\end{abstract}

Keywords Professionalism · Responsibility · Moral pluralism · Agri-food · Animal welfare

\section{Introduction: From footnotes to public debate}

The combination of veterinary medicine, philosophy and animals still remains special. Traditionally, mainstream philosophy pays scant attention to animals. The ancient Greeks did reflect on the position of the animal. Aristotle, for instance, combined biology with philosophical thought on animals in his works History of Animals, Parts of Animals and Generation of

Franck L. B. Meijboom

f.1.b.meijboom@uu.nl

1 Ethics Institute and Faculty of Veterinary Medicine, Utrecht University, Yalelaan 2, NL-3584 CM, Utrecht, The Netherlands 
Animals. According to him, "in every animal there is something natural and good" (Balme 1992, 645a 21). On the whole, though, Schopenhauer's expression seems to be appropriate: posted at the entrance of Western ethics there was a sign: "Animals should stay outside" (Schopenhauer, 1976/1840). Even Bentham, who has become famous for claiming that "...the question is not, Can they reason? nor, Can they talk? but, Can they suffer?" only related this claim to animals in a footnote to his Introduction to the Principles of Morals and Legislation (1789, Chapter 17). This position of the animal in the footnotes of Western philosophy remains up until today. Modern philosophers like John Rawls or Thomas Scanlon have not much to say about animals. Their contractual accounts do not exclude the idea that animals are morally relevant, but mainly focus on the morality of what we owe to human beings (cf. Scanlon 1998, 179).

At the same time, philosophical reflections still seem to be marginal or at footnote level in veterinary medicine as well. In spite of developments since the 1970s that put professional ethics on the agenda (e.g., Fox 1984; Heeger 1980; Rollin 1978; 1983; Rozemond 1985; Visser and Grommers 1988), incorporating ethics as a basic aspect of the veterinarian science and profession is still an ongoing process. This process is complicated in many ways. First, the competence of veterinarians to deal with ethical issues is sometimes questioned by colleagues (cf. Heath 2002, 476) or is equated with providing veterinary care (Woods 2013). Second, as far as veterinarians show a competence to deal with ethical issues there is a plurality of views within the profession. In spite of existing international treaties and legal frameworks, professional codes and guidelines (e.g., FVE 2012), veterinarians in practice differ in the way they construct moral problems, or in the way they recognize a situation as morally problematic (Morgan 2009, 172). As Sandøe and Morgan accurately point out: "there is no longer (if there ever was) a single professional ethic shared by all those working in the field of veterinary medicine" (2008, 54).

This all stands in a context of more than 50 years of public reflection and discussion on the moral position of animals and the ethical (un)acceptability of many types of animal use, including animals for food production. Rather than through philosophy or veterinary science, public concern with animals started out from publications like Ruth Harrison's Animal Machines (1964), one of the first to put welfare problems with respect to animals kept in intensive production systems on the agenda. The resulting debates and the increasing concern in society about the treatment of animals had and still have a direct influence on the veterinarian profession. It forced the profession to reply and take ethical positions in the debate. This resulted in the well-known challenge for the veterinarian to find a balance between the interests of the patient and the client. Once the animal is recognized as a being that is morally considerable for its own sake, the veterinarian has a duty to take the patient's interests seriously. However, this recognition does not dissolve one's duties toward the clients as the owner of the animal. When the interests or duties conflict the veterinarian needs systematic moral reflection to act as a professional.

In this paper, I first claim that this classical view on the moral problems of the veterinarian is complicated by moral tensions that are specific to current farm animal practice, specifically to veterinary care in the context of animals that are used for food production. Second, I claim that this requires further innovation in veterinary ethics, which implies additional reflection from philosophy and veterinary professionals.

To substantiate the first claim, I introduce and discuss two characteristics that influence the work of the veterinarian professional in livestock farming. First, I argue that the plurality of views on the moral standing of animals is especially a problem in the context of farm animal 
health and welfare. A second characteristic is the trend related to changes in the public expectations with regard to the veterinary profession.

To elaborate on the second claim, I argue that three scenarios that suggest how the veterinarian can deal with this moral pluralism and the changing public expectations are undesirable. I show that they either deny the moral pluralism or the genuine moral character of the professional responsibility of a veterinarian. A different frame is needed. In search for such a frame, I claim that professional codes or standards are important, but are insufficient to deal with the mentioned characteristics. To function as professional who can deal with a plurality of moral views and changing public expectations, professional integrity is a key concept. At the end of this paper I argue that veterinarians working in the agri-food sector need to maintain an independence from the concerns and interests of stakeholders to effectively deal with the problems of moral plurality and changing expectations.

\section{Plurality as a Practical Problem}

It is evident that animals have a special position in Western society and that human-animal interactions are considered to be important and valuable (cf. Herzog 2011). However, a public and shared understanding about the moral position of animals is still lacking. As a result, there still is a genuine public debate about whether and, if so, why animals are morally considerable for their own sake. Furthermore, this debate has a direct influence on discussions about the public acceptability of different types of animal use. Especially for this latter debate Fraser's observation is still correct that "debate is perhaps too mild a term. The treatment and use of animals has long been a subject of passionate disagreement in Western culture" $(2001,634)$.

This holds for every kind of interaction with animals. However, especially in the case of livestock farming the plurality of moral views directly influences the daily work of veterinarians. The plurality becomes evident at three levels. First, farmers, as the main clients represent the whole spectrum of views on the moral status of animals ranging from 'beings with mere instrumental value only' to animals that should be addressed with care and respect due to their intrinsic value (cf. De Rooij et al. 2010). Second, veterinarians work in a public context in which consumer/citizens also have a wide range of views on what is acceptable with regard to farm animals, including the view that animals have dignity and rights, and therefore should not be used for food production at all. Finally, because food production is a global activity, veterinarians are not only confronted with the mentioned "passionate disagreement in Western culture", but also with views on the position of animals in Latin America, in Russia or in China (cf. Meijboom and Li 2015).

Consequently, the above-mentioned moral plurality within the veterinary profession (e.g., Morgan 2009; De Graaf 2005) is confronted with a similar or even more profound plurality in farmers and society. This is problematic, because veterinarians can neither as individuals nor as a profession change this plurality on their own. Nonetheless, it directly influences their daily professional work. For instance, more than once farmers' expectations conflict with the veterinarian's moral standards, e.g., when vets are requested to kill calves that are healthy but underweight and hence economically unfit for production. Or when practices such as the separation of cow from calf - common procedure for farmer and veterinarian - are (suddenly) publicly criticized in the media. This is the first sign that the veterinarian specialized in livestock should be enabled to deal with this moral tension, and that this demands further reflection within the profession. 


\section{Professional Responsibilities: Changes and Challenges}

Next to the problem of moral plurality, the work of the veterinary profession is characterized by a change in public expectations. It holds for each profession that responsibilities can and do change over time (cf. Carr 1999) due to changes in their practice or in society. In general it is important for professions to "stay in accord with social ethics, or risk losing their autonomy" (Rollin 2004, 955). In the course of the last decades veterinarians working in the field of animal food production witnessed and continue to see a lot of change. These changes have their impact on their responsibilities. The general and widely accepted responsibility with regard to animal health and a focus on curative medicine is changing and has been challenged in three ways.

\section{Between Global Demands and Local Care}

To begin with, one source of new expectations starts in the global character of food production. Farming is no longer a national or regional activity only. European or even global guidelines and demands immediately influence choices made on an individual farm. This has a direct impact on the work of the veterinarian who has to operate on a farm that still is local, but at the same time is intrinsically related to all kinds of international economic drivers and regulations. Furthermore, these farms tend to become bigger. In many cases this does not immediately result in more work for the veterinarian. This is the result of another change of expectations: the veterinarian has to deal with animal health questions on a collective level rather than on an individual level. For instance, confronted with a farm with thousands of broilers or pigs, providing individual care turns out to be extremely difficult. Due to global economic drivers, farmers tend to perceive their animals as a collective rather than as individuals that are entitled to individual care.

The shift to global questions and collective care seems to result in a mismatch with the veterinarian, who is traditionally trained as an expert in the field of animal health, with a specific focus on the individual animal and who works locally. It challenges traditional views on professional responsibility that focus on the care for the health of individual animals. Such views immediately prompt the questions "whose health?" and "how do you make an assessment if one has to choose between individual and collective animal health?" Sometimes, pragmatic or innovative solutions are proposed to deal with these questions, for instance by using information technologies to monitor the health of large groups of animals. However, these options often turn out not be morally neutral. A clear example is the use of antibiotics as a kind of preventive medicine. This was introduced as an interesting option that was economically feasible and enables a vet to provide care to the animals. However, it overlooked the wider consequences on public health. Consequently, the animal production sector is confronted with a growing public concern with regard to the overuse of antibiotics (Clark et al. 2016) and recent policy on this theme in various European countries. This shows that the veterinary profession has to cope with both a changing context of animal production and a change in what society expects of veterinarians. This requires further reflection on veterinary responsibility.

\section{Animal Welfare}

Second, in the last decades veterinarians recognized that a duty of care is not restricted to animal health, but equally includes attention to animal welfare. This requires that the 
veterinarian is able to assess the welfare status of animals. Currently, animal welfare is often made operational in terms of attention to the so-called 'Five Freedoms' as adopted by the Farm Animal Welfare Council (FAWC 2009, FVE 2012). ${ }^{1}$ But this view on animal welfare gives rise to two difficulties. First, the veterinarian is frequently confronted with farm animal practices in which, due to the commercial interests of the farmer, the five freedoms are not fulfilled. This raises the question of how to deal with these situations: should the veterinarian take the responsibility to improve animal welfare within the existing practice or does it require public disapproval of the practice as such? Such questions are not always easy, but they make clear that veterinarians as individuals and the profession as a whole should be able to deal with these situations in a deliberate way. Moreover, the assessment of animal welfare is complicated by the fact that the animal production chain has many links, while an individual veterinarian is usually involved with only one or two of these links. For instance, during the lifetime of a pig many veterinarians are involved: in breeding, farming, transportation and slaughter. Consequently, none of them is likely to have a complete picture of the animal's welfare. For instance, the veterinarian who assesses the slaughter process of the pig often does not know much about the welfare of animal before it enters the slaughterhouse. The vet may even live in a different country than the vet who was responsible during the breeding of the pig six months earlier. This makes the position of veterinarians vulnerable, because other stakeholders, such as retailers or breeding companies have a better view on the animal chain. It even raises a serious question about the ability to fulfill the professional responsibility with regard to animal welfare, especially if welfare is defined broader than just a focus on acute stress (Fraser et al. 1997, 2013). For instance, when elements of positive feelings and adaptive capacities are incorporated into the concept of animal welfare (cf. Ohl and van der Staay 2012; Ohl et al., 2017), assessment during the animal's life is essential to safeguard its welfare. Consequently, veterinarians have to further reflect on the definition of welfare, and should discuss a strategy that enables them to assess welfare even if the animal production chain remains fragmented.

\section{Public Health and One Health}

A third challenge is posed by the fact that veterinarians are no longer expected to deal with animal related issues only. The impact of livestock farming on human health is considered to be a shared responsibility of the veterinarian and human medicine. This becomes explicit in discussions about the effect of the use of antibiotics in veterinary medicine on antibiotic resistance in humans and on the environment (cf. Speksnijder et al. 2017). Another example are the debates on the impact of dust emissions from livestock on human health (cf. Baliatsas et al. 2017).

This change of expectations with regard to public health is further complicated in two ways. First, the global character of food production impinges on the responsibilities of the veterinary profession. Veterinarians are confronted with international requirements concerning global public health even if they work on a local farm. Conversely, local decisions on a farm may have an impact on global public health. Emerging infectious diseases, especially zoonoses, are well-known examples rendering interaction between local farms and international animal and human health very evident. A local outbreak of, for instance, a zoonotic type of Avian

\footnotetext{
${ }^{1}$ At this point I leave the discussion about the evident shortcomings of a strict five freedom approach to animal welfare. Also the FAWC (2009) recognizes the shortcomings.
} 
Influenza may have direct impact on public health measures in other countries in order to prevent further infection. Consequently, the veterinarian needs the competence to assess both the local (public) health risks and the international context. Even though this field is currently covered by many laws and regulations, there still is room for individual and professional assessment by veterinarians.

Second, the responsibility of veterinarians with questions of public health are increasingly framed in terms of the so-called One Health approach. This approach aims for a more inclusive and multispecies view on health (cf. AVMA 2008). This implies that the veterinarian cannot limit the assessment of his actions to the clients (farmer) and the patient (animal). Osburn et al. claim that "veterinarians have pivotal obligations, opportunities, and contributions to make in enhancing public health, recognising and responding to zoonotic disease transmission, maintaining food and water quality, and promoting wildlife and ecosystem health" $(2009,481)$. This One Health approach entails a number of normative questions pertinent to the responsibility of the veterinarian, including assumptions about health, the moral importance of animals and the environment, and questions of how to balance public health, the (economic) value of farming, and animal health and welfare (cf. Leach and Scoones 2013; Nieuwland and Meijboom 2015; Verweij and Bovenkerk 2016). This shows that also at this level veterinarians have to reflect on their new position and on the way to deal with the moral questions that come with One Health in the context of veterinary medicine.

\section{From Problems to Opportunities}

The local farm animal veterinarian who aims to care for the individual animal still has an important role to play in the practice of farm animal veterinary care. However, performing as a professional currently implies that one also has the competence to take collective and global perspectives into account, and has a responsibility that includes care for animal welfare and public health. To a certain extent this may also hold for veterinarians who are specialized in companion animal health or work in the field of laboratory animal science. Still, the combination of questions and the extent to which the veterinarian is confronted with them are rather specific for professionals in the field of farm animal health. As has been recognized, this has direct consequences for veterinary ethics (cf. Rollin 1999, 2004). Professional ethics in the field of farm animal health is no longer restricted to the traditional challenge to find a balance between the interests of the patient and the client, but also includes an ethical assessment of a much broader web of stakeholders and values.

It would however be too easy to claim that therefore the veterinarian is faced with nothing but problems. This new context also results in opportunities for veterinarians to play a more active role. I will give two examples. First, given the public concern, European governments concluded that animal care in situations of infectious diseases can no longer be left to the discretion of the individual farmer only (Cf. Speksnijder et al. 2015; Levy 2014). As a result, policies and regulations have been drafted. Even though veterinarians are not required to be legal experts, they can play a more prominent role in this context. They can do so by taking a more active stance in advising farmers to implement laws and regulations and translate international guidelines to a local level, in a way that still take the interests of both the animal and the farmer into account. This role can be based on the expertise in veterinary medicine, but requires that one also is able to deal with conflicting values and interests. Based on this position and expertise, it becomes possible to play an intermediary role and also play a role in 
advising governments. From this perspective, rather than being squeezed between conflicting interests, the veterinarian can act as an independent professional, who has direct knowledge of the daily practice, but also a clear eye for public concerns. Professional veterinary organizations such as the Federation of Veterinarians of Europe (FVE) already take such a role. However, this could be further elaborated by deliberately and more explicitly including the ethical dimension. This is an inherent aspect of dealing with infectious animal diseases without a direct and shared public position.

Second, veterinarians can play an important role in the One Health debate or in the discussion on the prevention and control of epizootic diseases. They can do so by showing that the value of public health is important, but not absolute. Veterinarians can bring the animal perspective into the debate. This does not imply the denial of the importance of public health, but can question the - often unreflected - tendency to give public health priority. In practice the supremacy of public health tends to lead to serious harm for animals. Veterinarians can help to start a more balanced discussion on and contribute to a One Health approach that genuinely helps in evaluating the interests of humans, animals and the ecosystem as a whole (cf. RDA 2016).

To my mind such opportunities are given with the changing professional context and expectations. To capitalize on them veterinarians should present and organize themselves as a real profession, including professional organizations, permanent education and internal guidelines. Most Western countries already have such a structure. However, veterinary organizations, including educational establishments, need to be more proactive in ethical debates, and take an independent position in the discussion and practice of livestock farming. Their message need not always differ from the views of farmers or consumers. Essential however is that they become a recognized, independent partner. Such recognition should be gained, not by way of a marketing strategy but by demonstrating how veterinarians reflect on and deal with the specific questions they face and the responsibilities they have.

However, at this point the problem of dealing with the plurality of views returns once again. Stressing the opportunities and the need to include the ethical dimensions more explicitly may seem to be frustrated by the moral pluralism in society and within the profession. Therefore, I propose a scenario that enables the veterinarian to take an active stance and can do justice to the moral pluralism. To clarify my position, I first sketch three undesirable scenarios to deal with the problem of moral pluralism and the ethical dimensions of the current veterinary profession.

\section{Three Scenarios and the Limits of a Professional Code}

Every veterinarian recognizes moral tensions when working with animals and their owners (cf. Sandøe and Morgan, 2008). As a result, different ways to deal with this problem can be recognized. I sketch three scenarios and argue that each of them has serious flaws.

The first scenario is acting like an ostrich. In this scenario one recognizes that as a veterinarian one is confronted with many conflicting interests and expectations. This is experienced as something that not only complicates working as a vet, but also distracts one from the core of the veterinary profession. One considers that the veterinarian is an expert in veterinary science and therefore should stick to empirical facts only. Ethics is a totally other realm and should be dealt with by society or philosophers rather than by veterinarians.

This way of thinking often results in an inward looking attitude of veterinarians and a strict focus on clinical problems only (Hellebrekers and Den Hertog 2008). The scenario solves the 
tensions, but has at least two serious problems. First, it is counter intuitive. Many veterinarians obviously feel the need to take the ethical dimension into account, and - as professionals experience difficult moments when they have to make decisions about, for example, whether or not to kill a pregnant animal. Second, philosophy of science shows that a strict watershed between ethics and science is not tenable (e.g., Briggle and Mitcham, 2012). Methods and approach in life or medical science always have normative dimensions, which entails that the notion of ethics as something one can take or leave is untenable (cf. Procter 1991).

A second scenario is that of the rabbit. From this view, dealing with ethical problems as such is not considered incompatible with veterinary medicine. However, once confronted with moral pluralism, the veterinarian freezes like a rabbit blinded by the poacher's torch. In this sense this scenario is fundamentally different from the first one in which one deliberately decides not get involved in ethical issues. In this case it just happens. Veterinarians can become paralyzed by the profound plurality of conflicting views. Since it seems impossible to satisfy the requirements of all involved stakeholders, vets sometimes indicate that, although they are professionals, they can no longer "determine the ways of thinking about problems which fall in their domain." (Dingwall and Lewis 1983, 5). As a result this frequently leads veterinarians to leave the practice or to shift to veterinary care for small companion animals. Given the huge impact on the individual veterinarian and his practice, it may be obvious that this scenario is unsuitable to deal with the problem of moral pluralism.

The third scenario seems more promising. This is the scenario of the chameleon. This is the trend of full accommodation to the (moral) norms and values of one of the stakeholders. Mostly this implies that the veterinarian accommodates his activities to the values and interests of the farmer. Accordingly, the veterinarian gets the role of service provider, who aims to act in the best interest of the farmer. In practice this turns out to be an efficient way of surviving moral pluralism, keeping a veterinary practice running, and being valued by the clients. Nonetheless, it raises two related problems. On the one hand, it becomes difficult to show the added value of the veterinarian as an academic professional next to other professionals in the field. For instance, in practice more than once the animal feed advisor, who is also an experienced service provider, starts to play an advisory role on topics that belong in the veterinarian realm, e.g., with regard to disease prevention or welfare management (cf. Derks et al. 2011; Wylick 2008). On the other hand, veterinarians run the risk to lose societally entrusted prerogatives such as the right to administer and prescribe medication. These rights are entrusted based on expertise, but also on certain levels of independence and impartiality. These criteria are under serious pressure if the veterinarian in practice follows the interests and values of the farmer only.

These three scenarios show how difficult it is to find a solution that does justice to (a) the genuine moral pluralism, (b) the ethical dimensions related to veterinary care, (c) the independent position of the veterinarian who takes the values of all parties into account, and (d) live up to the societal expectations. To find a way to deal with this situation, the importance of Professional Codes of Conduct is often mentioned. Veterinarians since long have professional codes. They are often considered as one of the constitutive elements in defining an occupation as a profession. The code formulates guidelines based on the core values and principles of a profession. This is very helpful in a context that is characterized by moral pluralism. It helps the individual veterinarian to make decisions. Furthermore, it gives a certain backing in discussions with other partners: your position is not just based on your opinion; it is the standpoint of the profession.

However, Professional Codes of Conduct alone cannot do the job. First, there is a practical problem: no general rule can completely prescribe how a professional should act. The well- 
known four principles of biomedical ethics (Beauchamp and Childress 2001), that are also often used in veterinary medicine, are a clear example. Even if we agree on, for instance, the importance of the principle of benevolence, it is not self-evident how a veterinarian in a specific context should interpret this principle once he is confronted with an owner who cannot pay for his services. Professional practices require the power of judgment in order to come to tailor-made interpretations of ethical principles in the context of a specific situation. This calls for moral competence and the ability to deal with the (conflicting) values at stake.

Second, being a professional implies more than following rules. I agree with Carr that the "precise codification or systematization of professional ethics" $(1999,45)$ is important, but there still is an obligation for the professional to make his own moral judgment rather than "accept merely at the bidding of others" $(1999,45)$. If the moral competence of the professional is perceived in this broader sense, professionals can play an active role in dealing with the ethical questions of their professional practice. Consequently, even with an ethical code the veterinarian needs moral competence that goes beyond obeying that guideline. Therefore, I end with some remarks on the importance of professional integrity.

\section{Professional Integrity as a Start}

The challenge for the veterinary profession is to find a balance between full accommodation and the problem of getting paralyzed by the profound plurality of conflicting views. Such a balance is not only relevant in dealing with the question of moral plurality, but is equally important while coping with the moral dimensions that come with the other challenges, i.e., the global character of animal production, animal welfare and One Health.

I propose an answer that starts in the notion of integrity. Calhoun defines integrity along the lines of three pictures. First, integrity can be defined in terms of the integrated self. In this picture, integrity is about "the integration of 'parts' of oneself ... into a whole." Integrity results, for instance, in the integration of speech and action, but also in the integration of a person's desires and commitments. The second picture links integrity to identity. In this view, 'integrity means fidelity to those projects and principles which are constitutive of one's core identity.' Finally, there is the 'clean-hands' picture of integrity. Integrity is closely related to the way a person deals with conflicts and disagreement. It is especially related to maintaining the purity of one's own agency in 'dirty-hands situations' (Calhoun 1995, 235). The aspects of integration, identity and coping with conflicts are helpful to approach the moral problems of the veterinarian. For the veterinarian profession it requires a (further) debate within the profession to identify and define those projects and principles which are constitutive of one's core professional identity. In other words, what are the tasks and aims that are essential for the veterinary profession as a whole, but also those that are specific to farm animal practice (and other veterinary businesses). These are not easy debates, because we have seen that the current developments challenge the traditional answers. However, current national and European examples show that it is possible to discuss this topic (e.g., BVA 2016; Bundestierärztekammer 2017; KNMvD 2017).

This emphasis on professional integrity is a necessary, but not a sufficient condition to deal with the moral tension related to veterinary care in animal production. If a vet only expresses his or her strong moral beliefs it may be as counterproductive for a profession as the chameleon scenario. Therefore a balance between accommodation and integrity is needed. From this perspective, accommodation is not just turning the professional into a service 
provider. It starts from one's own moral view that follows from professional integrity, but can in cases of disagreement incorporate a "stance of modest respectful disapproval" (Postow 2007, 191). This implies that one makes "special efforts to 'think outside the box' to find a way to accommodate [his] moral view in the particular concrete case that confronts them" (ibid, 202). The veterinarian should be open to the plurality of moral beliefs and should be prepared to change his view, and be willing to actively search for new ways to deal with the conflicting expectations. The difference with the chameleon scenario is that by including integrity, the professional can formulate constraints to the demand of accommodation in a way that make choices not arbitrary.

In practice the veterinarian's commitment to the combination of animal welfare, animal health and public health could serve as source to formulate such constraints. No one else in society has this specific task and role combined with expertise and education. Commitment to this core can serve as the basis for professional integrity and can enable individuals and the profession to operate in the complex context of livestock farming. On the one hand, a clear view on the veterinarian's core commitments enables society to understand what can be expected of this profession. This is crucial for trust, which is essential for being entrusted by society with professional autonomy (cf. Meijboom and Stafleu, 2016). On the other hand, this commitment enables the veterinarian to define the room for accommodation toward the views and expectations of other stakeholders. It is important to stress that the commitment to the professional aims and principles is not a safeguard for a profession to keep its hands clean. Integrity does not require that right and wrong are predetermined or formulated in strict guidelines. Professional integrity requires moral reflection on how the profession's principles have to be interpreted given the conflicting interest, and to make use of one's discretionary power. It remains possible to adjust one's acts to the specific interests and expectations at stake. The point is that integrity in terms of a commitment to the professional aims and principles helps the individual professional to motivate his/her actions and to show why decisions are not just arbitrary or opportunistic.

The inclusion of professional integrity will not make moral pluralism disappear. Neither will it help us to predict what changes the future will bring, nor what the public is going to expect from veterinarians. All the more reason to include professional integrity, so that the profession becomes known to actively reflect on its moral position, prepared to formulate practical answers when confronted with a plurality of moral opinions, and able to specify constraints when faced with new expectations and disagreement.

\section{Conclusion}

In this paper I argued that veterinary ethics in the context of food production is a special case that is in need of additional reflection from philosophy and veterinary professionals. The direct impact of the problem of moral plurality on the veterinary practice, and the changing expectations that the veterinary profession is confronted with substantiate this claim. I showed that denying the moral problems will not work in the long run. By initiating systematic reflection on the importance of professional integrity seems most helpful.

In practice this implies that (a) veterinarians have to actively cooperate with each other on moral and public issues, (b) continuously work on the definition and translation of their core values and (c) formulate guidelines that enable individual veterinarians to play an independent role in the practice of animal production. Only as committed, but independent professionals in 
the agri-food sector can veterinarians deal with (! not solve) the problems of global moral plurality, the complex character of a sector with local farms and international trade, questions of One Health, and the related shifting expectations in society.

Open Access This article is distributed under the terms of the Creative Commons Attribution 4.0 International License (http://creativecommons.org/licenses/by/4.0/), which permits unrestricted use, distribution, and reproduction in any medium, provided you give appropriate credit to the original author(s) and the source, provide a link to the Creative Commons license, and indicate if changes were made.

\section{References}

AVMA American Veterinary Medical Association. 2008. One Health: a new professional imperative, One Health Initiative Task Force final report, Washington, DC.

Baliatsas, C., F. Borlée, C.E. van Dijk, B. van der Star, J.-P. Zock, L.A.M. Smit, P. Spreeuwenberg, D. Heederik, and C.J. Yzermans. 2017. Comorbidity and coexisting symptoms and infections presented in general practice by COPD patients: Does livestock density in the residential environment play a role? International Journal of Hygiene and Environmental Health 220 (4): 704-710 ISSN 1438-4639.

Balme, D.M. 1992. Aristotle. De Partibus Animalium I and De Generatione Animalium I (with passages from II. 1-3) With a Report on Recent Work and an Additional Bibliography by A. Gotthelf: Oxford University Press.

Beauchamp, T.L., and J.F. Childress. 2001. Principles of Biomedical Ethics, 5ed. Oxford: Oxford University Press. Briggle, A., and C. Mitcham. 2012. Ethics and science. In An introduction. Cambridge: Cambridge UP.

Bundestierärztekammer. 2017. Tierärztliche Bestandsbetreuung 2.0: Garant für Tiergesundheit und Tierwohl. Eine Positionsbestimmung der Ad-hoc Arbeitsgruppe Bestandsbetreuung. Berlin: BTK e.V., http://www. bundestieraerztekammer.de/downloads/btk/fachausschuesse/Bestandsbetreuung_final.pdf (last accessed 26 July 2017).

BVA. 2016. Vets speaking up for animal welfare. BVA animal welfare strategy. London: British Veterinary Association, https://www.bva.co.uk/uploadedFiles/Content/News,_campaigns_and_policies/Policies/Ethics_ and_welfare/BVA-animal-welfare-strategy-feb-2016.pdf (last accessed 26 July 2017).

Calhoun, C. 1995. Standing for Something. The Journal of Philosophy 92 (5): 235-260.

Carr, D. 1999. Professional education and professional ethics. Journal of Applied Philosophy 16 (1): 33-46.

Clark, B., G.B. Stewart, L.A. Panzone, I. Kyriazakis, and L.J. Frewer. 2016. A Systematic Review of Public Attitudes, Perceptions and Behaviours Towards Production Diseases Associated with Farm Animal Welfare. Journal of Agricultural and Environmental Ethics 29: 455-478. doi:10.1007/s10806-016-9615-x.

De Graaf, G. 2005. Veterinarians' discourses on animals and clients. Journal of Agricultural and Environmental Ethics 18 (6): 557-578.

De Rooij, S.J.G., C.C. De Lauwere, and J.D. van der Ploeg. 2010. Entrapped in group solidarity? Animal welfare, the ethical positions of farmers and the difficult search for alternatives. Journal of Environmental Policy \& Planning 12 (4): 341-361.

Derks, M., T. van Werven, W.D.J. Kremer, and H. Hogeveen. 2011. 'Veterinary on-farm counselling on dairy farms: the veterinarians' vision. In Udder Health and Communication, ed. H. Hogeveen and T.J.G.M. Lam, 179-185. Wageningen Academic Publishers: Wageningen.

Dingwall, R., and P. Lewis, eds. 1983. The Sociology of the Professions: Doctors, Lawyers and Others. London: Macmillan.

FAWC, Farm Animal Welfare Council. 2009. Report on Farm Animal Welfare in Great Britain: Past, Present and Future, Department for Environment. London: Food \& Rural Affairs.

FVE, Code of Conduct \& Veterinary Act, 2012 www.fve.org (last accessed 26 July 2017).

Fox, M.W. 1984. Towards a philosophy of veterinary medicine. The Veterinary Record, 115(1):12-13.

Fraser, D., D.M. Weary, E.A. Pajor, and B.N. Milligan. 1997. A scientific conception of animal welfare that reflects ethical concerns. Animal Welfare 6: 187-205.

Fraser, D., I.J.H. Duncan, S.A. Edwards, T. Grandin, N.G. Gregory, V. Guyonnet, P.H. Hemsworth, S.M. Huertas, J.M. Huzzey, D.J. Mellor, J.A. Mench, M. Špinka, H.R. Whay. 2013. General Principles for the welfare of animals in production systems: The underlying science and its application. The Veterinary Journal 198(1):19-27.

Heath, T.J. 2002. Longitudinal study of veterinarians from entry to the veterinary course to 10 years after graduation: attitudes to work, career and profession. Australian Veterinary Journal 80 (8): 474-478.

Heeger, F.R. 1980. Norms and good reasons. Tijdschrift Voor Diergeneeskunde. 105 (4): 147-153.

Hellebrekers, L.J., and A. den Hertog. 2008. The veterinarian in 2015. Tijdschrift voor Diergeneeskunde. 133 (10): 446-447. 
Herzog, H. 2011. Some we love, some we hate, some we eat. Why it's so hard to think straight about animals. New York: HarperCollins Publishers Inc.

KNMvD. 2017. Samen werken we aan duurzaamheid, Houten: Koninklijke Maatschappij voor Diergeneeskunde, https:/www.knmvd.nl/item/10884114/Samen-werken-we-aan-duurzaamheid (Last Accessed 26 July 2017).

Leach, M., and I. Scoones. 2013. The social and political lives of zoonotic disease models: narratives, science and policy. Social Science \& Medicine 88: 10-17.

Levy, S. 2014. Reduced Antibiotic Use in Livestock: How Denmark Tackled Resistance. Environmental Health Perspectives. 122 (6): A160-A165. doi:10.1289/ehp.122-A160.

Meijboom, F.L.B., and F.R. Stafleu. 2016. Farming ethics in practice: From freedom to professional moral autonomy for farmers. Agriculture and Human Values 33 (2): 403-414. doi:10.1007/s10460-015-9641-8.

Meijboom, F.L.B., and J. Li. 2015. Animal husbandry and food production in China and Europe: a shared moral problem? In Know your food: Food ethics and innovation, ed. D. Dumitras et al., 150-154. Wageningen: Wageningen Academic Publishers.

Morgan, C. 2009. Stepping up to the plate: animal welfare, veterinarians, and ethical conflicts. $\mathrm{PhD}$ thesis. University of British Columbia, Canada. www.landfood.ubc.ca/animalwelfare/publications/pdfs/theses/Carol_Morgan Thesis.pdf. [21.7.2015].

Nieuwland, J., and F.L.B. Meijboom. 2015. One health as a normative concept: implications for food safety at the wildlife interface. In Know your food: Food ethics and innovation, ed. D. Dumitras et al., 132-137. Wageningen: Wageningen Academic Publishers.

Ohl, F., R. Putman, and members of DWM Utrecht. 2017. The Biology and Management of Animal Welfare. Dunbeath: Whittles Publishing.

Ohl, F., and F.J. van der Staay. 2012. Animal Welfare: At the interface between science and society. The Veterinary Journal 192: 13-19.

Osburn, B., C. Scott, and P. Gibbs. 2009. One World - One Medicine - One Health: emerging veterinary challenges and opportunities. Revue scientifique et technique - Office international des épizooties. 28 (2): $481-486$.

Postow, B.C. 2007. Toward Honest Ethical Pluralism. Philosophical Studies 132 (2): 191-210.

Procter, R. 1991. Value-free Science?: Purity and Power in Modern Knowledge. Cambridge: Harvard University Press.

RDA/ Council on Animal Affairs. 2016. One Health; A Policy Assessment Framework, Den Haag: RDA ( www. rda.nl ).

Rollin, B.E. 1999. An Introduction to veterinary ethics: theory and cases. Ames: Iowa State University Press.

Rollin, B.E. 2004. Annual meeting keynote address: animal agriculture and emerging social ethics for animals. Journal of Animal Science 82 (3): 955-964.

Rollin, B.E. 1978. Updating veterinary medical ethics. Journal of the Am Vet Med Assoc. 173 (8): 1015-1018.

Rozemond, H. 1985. Veterinary conduct and animal welfare. In Advances in animal welfare science, ed. M.W. Fox and L.D. Mickley, 255-265. Washington, DC: The Humane Society of the United States.

Sandøe, P., and C. Morgan. 2008. The role of veterinarians and other animal science professionals. In Ethics of Animal Use, ed. P. Sandøe and S. Christiansen, 49-65. Blackwell Publishing: Oxford.

Scanlon, T.M. 1998. What we owe to each other. Cambridge: Belknap Press of Harvard University Press.

Schopenhauer A. 1976 / 1840. Über die Grundlage der Moral, in Sämtliche Werke, Band I, Stuttgart/Frankfurt am Main.

Speksnijder, D.C., H. Graveland, I.A.J.M. Eijck, R.W.M. Schepers, D.J.J. Heederik, Th.J.M. Verheij, and J.A. Wagenaar. 2017. Effect of structural animal health planning on antimicrobial use and animal health variables in conventional dairy farming in the Netherlands. Journal of Dairy Science 100 (6): 4903-4913 ISSN 00220302 .

Speksnijder, D.C., D.J. Mevius, C.J.M. Bruschke, and J.A. Wagenaar. 2015. Reduction of Veterinary Antimicrobial Use in the Netherlands. The Dutch Success Model 62 (s1): 79-87.

Verweij, M.F., and B. Bovenkerk. 2016. Ethical Promises and Pitfalls of OneHealth. Public Health Ethics 9 (1): $1-4$.

Visser, M.B.H., and F.J. Grommers, eds. 1988. Dier of ding. Objectivering van dieren. Wageningen: Pudoc.

Woods, A. 2013, The History of Veterinary Ethics in Britain, ca.1870-2000. In C.M. Wathes, S A. Corr, S.A. may, S.P. McCulloch and M.C. Whiting. (Eds.). Veterinary \& Animal Ethics: Proceedings of the First International Conference on Veterinary and Animal Ethics, September 2011, First Edition. Blackwell Publishing Ltd., 3-18.

Wylick, E. Van. 2008. Advies van dierenarts iets lager gewaardeerd dan advies van voeradviseur. Tijdschrift voor Diergeneeskunde 133 (21): 913. 